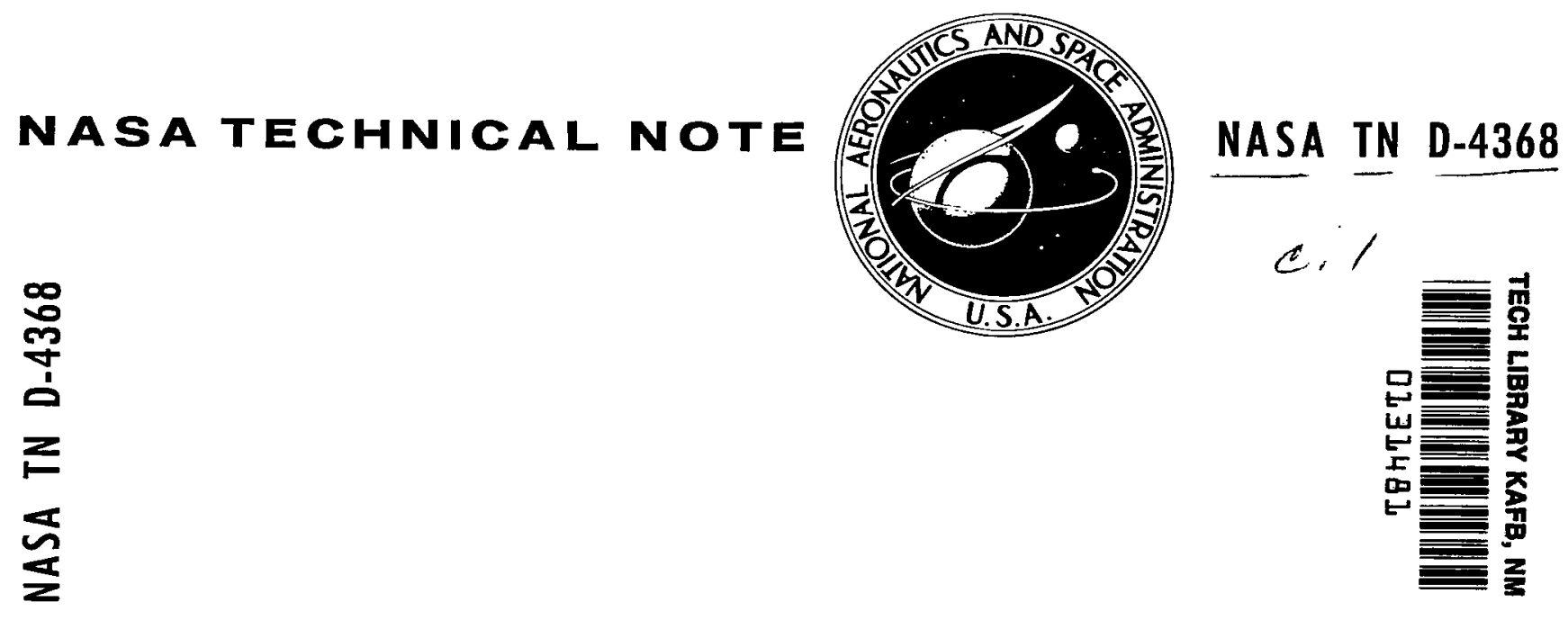

LOAN COPY: RETURN TO

AFWL [WLIL-2]

KIRTLAND AFB, $N M E$

\title{
ELECTRICAL PROPERTIES OF
}

XENON-FILLED THERMIONIC

DIODES IN RADIATION FIELD

OF A NUCLEAR REACTOR

by Ralph Forman

Lewis Research Center

Cleveland, Obio

NATIONAL AERONAUTICS AND SPACE ADMINISTRATION

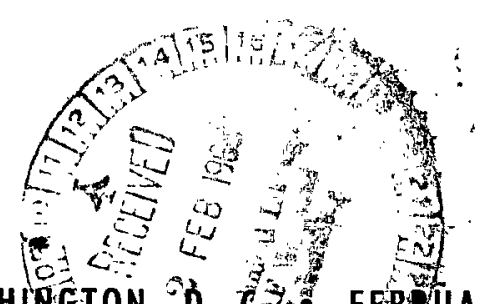

- WASHIRGTON, D. COA FEBTUARY 1968 
ELECTRICAL PROPERTIES OF XENON-FILLED THERMIONIC DIODES IN RADIATION FIELD OF A NUCLEAR REACTOR

By Ralph Forman

Lewis Research Center

Cleveland, Ohio

NATIONAL AERONAUTICS AND SPACE ADMINISTRATION

For sale by the Clearinghouse for Federal Scientific and Technical Information Springfield, Virginia 22151 - CFSTI price $\$ 3.00$ 


\title{
ELECTRICAL PROPERTIES OF XENON-FILLED THERMIONIC DIODES \\ IN RADIATION FIELD OF A NUCLEAR REACTOR
}

\author{
by Ralph Forman
}

Lewis Research Center

\section{SUMMARY}

Experimental data on nuclear-irradiated xenon-gas-filled thermionic diodes are presented. The characteristic curves for the irradiated diodes were studied as a function of xenon pressure ( 4 to 300 torr $\left(5 \times 10^{2}\right.$ to $\left.4 \times 10^{4} \mathrm{~N} / \mathrm{m}^{2}\right)$ ), nuclear radiation intensity (gamma dose rate $10^{8}$ to $6 \times 10^{8} \mathrm{rads} / \mathrm{hr}\left(10^{6}\right.$ to $6 \times 10^{6} \mathrm{~J} /(\mathrm{kg})(\mathrm{hr})$ )), emitter temperature $\left(1000^{\circ}\right.$ to $\left.1200^{\circ} \mathrm{C}\right)$, and electrode spacing $(0.025$ to $0.75 \mathrm{~cm})$. Some interesting breakdown phenomena occurred at voltages much lower than the first excitation potential. Some of the breakdown effects showed characteristics similar to those obtained in lowtemperature cesium thermionic converters. There are regions corresponding to the unignited mode, preignition, and the ignited mode. In some cases, depending on the choice of radiation intensity, xenon pressure, and interelectrode spacing, these breakdown modes occur at applied voltages as low as 1 volt.

\section{INTRODUCTION}

The objectives of this study are (1) to obtain a better understanding of the physical processes responsible for the operation of a nuclear thermionic conversion device and (2) to obtain information on the feasibility of a noncesiated nuclear thermionic conversion device. An experimental study of inert-gas-filled thermionic converters, in a nuclear reactor environment, was established to meet some of these goals. The purpose of this research is to bypass some of the problems which arise in the basic study of cesium thermionic devices. The complexity in their behavior arises from the unusual nature and high chemical activity of cesium. Normally, in a study of a given experimental phenomenon which is controlled by numerous parameters, it is desirable to design the experiment in such a manner that a given parameter can be varied while the others are held constant. This technique is not amenable to studies of cesium therm- 
ionic converters. In general, changing one variable in such a device (e.g., temperature of the emitter) changes many other parameters which control the operation (e.g. , work function of the emitter and surface ionization effects). A study of nuclearirradiated xenon-filled thermionic diodes was established to eliminate some of these difficulties in the hope of obtaining a more basic understanding of thermionic conversion.

Since the inert gases are extremely stable and have relatively high ionization potentials, they differ from cesium in that their thermal ionization and surface adsorption effects are negligible. The gas in the interelectrode space of the inert-gas-filled diode is ionized by inserting the tube into a nuclear reactor environment. Nuclear radiation from the reactor (e.g., gamma rays and high-energy secondary electrons) ionizes the gas and generates a plasma which neutralizes space charge effects. Such a device can be used to obtain a better understanding of the effect of design changes on nuclear thermionic diode performance. In this case, experimental parameters (e.g., work function and temperature of emitter and collector, interelectrode distance, pressure of gas, and intensity of nuclear radiation) can be individually varied, and their influence on the output current and the voltage of the device can be evaluated separately.

Measurements of inert-gas-filled thermionic diodes in a nuclear reactor environment were previously reported by the author (ref. 1). This previous work was done in diodes contained in quartz envelopes. These experiments showed that the conductivity of the plasma between the electrodes increased monotonically with radiation dose rate. In addition, some unusual electrical breakdown effects were observed. These initial experiments furnished limited information because the electrode temperatures could not be directly measured during the reactor tests. The present work was undertaken to do a more conclusive study of phenomena in a nuclear-generated gas plasma with a more versatile thermionic research diode. New features of the design are that (1) the diode is enclosed in a stainless-steel container, (2) electrode temperatures were directly measured with Chromel-Alumel thermocouples, and (3) techniques for collector cooling were incorporated in the design of close-spacing diodes.

The present experiments can be considered an extension of the earlier studies because they had the following features in common. The thermionic emitter (or cathode) employed was an electrically heated unipotential impregnated cathode which normally operates at about $1100^{\circ} \mathrm{C}$. The collector (or anode) was molybdenum, and xenon ( 4 to 300 torr $\left(5 \times 10^{2}\right.$ to $\left.\left.4 \times 10^{4} \mathrm{~N} / \mathrm{m}^{2}\right)\right)$ was used as the filling gas. In addition, all diodes were irradiated to a maximum gamma dose of about $6 \times 10^{8}$ rads per hour $\left(6 \times 10^{6} \mathrm{~J} /(\mathrm{kg})(\mathrm{hr})\right)$ in the core of a 5.0 megawatt swimming-pool-type nuclear reactor.

The conductivity of the irradiated xenon plasma, generated between electrodes, was determined by measuring the current voltage characteristics of the diodes as a function of gas pressure, emitter temperature, electrode spacing, and radiation dose rate. The data showing the variation of current voltage characteristic with variation of the pre- 
ceding parameters are presented. Early electrical breakdown, at applied voltages below the first excitation potential, was carefully investigated. Some of the characteristics measured were similar to those obtained from low-temperature cesium converters by other investigators. There are regions corresponding to the unignited mode, preignition, and the ignited mode.

\section{EXPERIMENTAL TECHNIQUES}

Two types of thermionic diodes were designed for these experiments, and are illustrated in figures 1 and 2. The cathode in both designs is identical. It is a Philips-type impregnated cathode (ref. 2) with an effective electron-emitting area of 3.55 square centimeters and an operating temperature of about $1100^{\circ} \mathrm{C}$. The anodes were constructed of molybdenum. Figure 1 presents schematically the diode design with a relatively large spacing of 0.75 centimeter between the electrodes. Cathode and anode temperatures were measured with the Chromel-Alumel thermocouples which were sheathed in stainless steel and grounded to the sheath at the hot junction. The goose-neck type of bend in the thermocouples permitted the thermocouple to expand and contract under thermal cycling without damaging either the thermocouple or the relative alinement of the electrodes. Seven tubes with this larger spacing were tested at various pressures of xenon. The anode temperatures of these diodes were less than $900^{\circ} \mathrm{C}$.

Figure 2 illustrates the type of tube designed for small cathode-anode spacing, from 0.025 to 0.1 centimeter. The closer spacing of these diodes required anode cooling to limit the anode temperature to $900^{\circ} \mathrm{C}$ or less when exposed to the maximum nuclear radiation. Even at this low temperature, the anode can begin to show some effects of thermionic emission because its surface becomes coated with barium from the cathode during the processing of the tube. The anode is cooled by the filling gas in the 0.025centimeter cooling gap. In normal reactor operation, the stainless-steel container is located in the reactor core coolant water. Because of the intimate contact between the alumina ring and the container, the alumina ring remains relatively cold. The xenon filling gas in the cooling gap then acts as a heat leak between the "'hot"' anode and the "cool" alumina ring. The number of tubes tested at interelectrode spacings of 0.1 , 0.05 , and 0.025 centimeter were six, six, and four, respectively.

The tubes presented schematically in figures 1 and 2 are shown unassembled in figures 3 and 4 , respectively.

The alinement of the close-spacing diodes was checked in a number of cases with either a radiograph or a gammograph (using iridium 192) technique. In most cases this checking was done before processing, but occasionally it was also done after processing and temperature cycling. Two radiographs were generally taken of the tube in planes 
which were mutually perpendicular. Even though the tube was assembled by spotwelding and alined by hand, relatively good alinement was obtained. This result is illustrated in figure 5 which is a radiograph of a diode with 0.05 -centimeter electrode spacing. The worst alinement situation occurred in tubes with 0.025 -centimeter separation between electrodes. In a typical example, the spacing in one plane of the radiograph was $0.025_{ \pm} 0.004$ centimeter, and in the other plane a misalinement was indicated with a reading of about 0.023 centimeter on one side and $0.033_{ \pm} 0.004$ centimeter on the other.

The tubes were processed in the following manner. They were baked out in a highvacuum system for a period of 25 to 30 hours at a temperature of $400^{\circ}$ to $425^{\circ} \mathrm{C}$. The cathodes were degassed at a temperature of about $1200^{\circ} \mathrm{C}$, and the anodes were degassed at temperatures in the range of $950^{\circ}$ to $1000^{\circ} \mathrm{C}$ for periods of 1 to 2 hours. The tubes were aged for various intervals of time, and their thermionic capability was checked periodically with a pulsed emission tester. (The pulser is a modified version of that described in a University of Minnesota report for the Air Force, AF 19(604)-3890, reports 4 and 10. It was modified and transistorized by Walter M. Krawczonek of Lewis.) The pulsed tester generated a saw-tooth voltage signal of 3 -microsecond duration with a repetition rate of 30 cycles or 3 cycles per second. The generator was designed to handle an emission capability of 10 amperes at a maximum applied voltage of $10 \mathrm{kilo-}$ volts. When the thermionic emission characteristics became stable at a sufficiently high emission capability, the tubes were filled with an appropriate pressure of xenon gas. A quartz spiral manometer technique (accuracy of measurement, \pm 0.5 torr $\left(70 \mathrm{~N} / \mathrm{m}^{2}\right)$ ) similar to that described in reference 3 was used. The high-purity xenon used was obtained in 1-liter glass break-seal bottles at atmospheric pressure. The only impurities reported were nitrogen at $5 \mathrm{ppm}$ and hydrogen at less than $5 \mathrm{ppm}$. After the tube was filled with xenon, pulse tests were again taken on the unirradiated tube. Some representative pulsed current-voltage characteristics for a diode before and after gas filling are illustrated in figure 6.

All diodes were irradiated in the core of a 5.0-megawatt swimming-pool reactor. They were mounted in rocket-type holders as shown in figure 7. Because of their plumblike design, the holders facilitated maneuvering the tubes under 7. 7 meters of water for insertion into test positions in the experimental reactor. These test positions were highflux holes of the reactor core; the irradiation took place at variable power levels from 1 to 5 megawatts. At maximum power, the neutron flux and gamma dose rate were approximately $8 \times 10^{13}$ neutrons per square centimeter per second and $6 \times 10^{8}$ rads per hour $\left(6 \times 10^{6} \mathrm{~J} /(\mathrm{kg})(\mathrm{hr})\right)$, respectively. Current-voltage characteristics were obtained by direct-current techniques. Since the distance from the core hole to the test table containing the electrical equipment was about 10 meters, two leads were attached to both the cathode and anode output lead. One lead (number 10 wire) carried the current, and the other (number 16 wire) was used to measure the voltage across the diode irrespec- 
tive of the voltage drop in the external current leads. The direct-current characteristics were displayed directly by the use of an $\mathrm{X}-\mathrm{Y}$ recorder.

\section{EXPERIMENTAL RESULTS AND DISCUSSION}

The solid portion of the curves in figure 8 illustrate the increased output current of the diode as a function of increasing nuclear radiation with the cathode temperature held relatively constant. The ordinate in this and all the other data curves up to figure 11 is the total current through the diode. To convert to cathode current density, the value of the ordinate should be divided by 3.55 , the cathode area in square centimeters. There is an interesting feature of the data in figure 8 besides the increased conductivity of the plasma, namely, that breakdown occurs at voltages much lower than the first excitation potential of xenon and at progressively smaller values of voltage with increasing radiation. The dashed portion of the characteristic curves denotes instability. The current instantaneously rises to a high value (order of amperes) which depends on the resistance of the lead wires to the tube and other variables. A more complete presentation and discussion of the breakdown characteristics will be given later in this section.

Figure 9 illustrates the influence of cathode temperature on irradiated diode characteristics. Increased cathode temperature results in higher current for a given applied voltage and also tends to give a lower breakdown voltage. The unstable portion of the characteristics is shown dashed. The breakdown is instantaneous, and the current rises to a given value which depends on the cathode temperature and the lead-wire resistance to the electrodes of the tube. The current finally attained a stable value after breakdown of 1,4 , and 5 amperes for curves $I$, $I$, and $I I I$ of figure 9 , respectively. If the applied voltage is then progressively lowered, the current remains stable but follows a different descending path ending on its respective characteristic at about 1.0 to 1.5 volts, as illustrated in figure 9.

The changes in irradiated diode characteristics with changes in xenon pressure and interelectrode spacing are illustrated in figure 10. The data in the three parts of figure 10 have a number of similarities: (1) the prebreakdown currents were in the range of 100 to 350 milliamperes for a small applied voltage and (2) the breakdown voltage, for each case, goes through a minimum value with pressure. However, the information in these curves indicates that the approximate pressure at which the minimum breakdown voltage occurs increases with decreasing electrode spacing.

In some of the curves shown in figure 10, relatively high reverse currents were obtained at negative voltages. These currents probably result predominantly from thermionic emission from the anode structure. This emission has two causes. First, the molybdenum anodes become coated with evaporated barium during the processing of the 
impregnated Philips cathodes. Second, gamma heating at 5. 0-megawatt reactor power leads to relatively high anode temperatures. The former condition results in a lowering of the anode work function, and the latter makes the anode an electron emitter. The anode temperature for curve VII in figure $10(\mathrm{~b})$ is not given because the anode thermocouple developed an open circuit at full reactor power.

The reproducibility of the data is illustrated by the curves in figure 10(a). The measurements to obtain curves I, III, and V were made 10 months after those made to obtain curves II and IV. During this interval, the reactor core test hole used was changed from one position in the center of the core to an adjacent position, and there was a minor change in the distribution of fuel. Curves II and III (approximately the same xenon filling) show that the breakdown voltage was not changed significantly even though the prebreakdown current values are different.

The concept of gas pressure as a quantitative experimental parameter deserves further comment. Theoretically, the pertinent physical parameter which should be controlled is the gas density between electrodes. An absolute quantitative relation between pressure and gas density is difficult to formulate because of the inherent complexity of the different tube designs. However, the volume between electrodes is small compared with the total volume of the experimental tubes, and the average temperature of each electrode at high reactor power is approximately the same in all tubes. Therefore, the gas pressure should be a meaningful parameter to qualitatively compare the effect of gas density on tubes with different electrode spacings.

Figure 10(c) also illustrates some interesting features associated with the breakdown phenomenon. As the voltage is increased from zero, the current rises in a stable manner until a voltage is reached at which breakdown occurs. At this point, instability sets in as indicated by the dashed portion of the curves, and the current rises to the order of amperes. If the applied voltage is then lowered, the current decreases stably along a completely different path and goes back into the initial characteristic at about 1 volt. This behavior is reproducible on repeated cycling.

These discharge phenomena at higher currents are illustrated in figure 11 . The unstable portion of the characteristic is shown as a dashed line in all the curves. The first stable value attained after breakdown is determined by the pressure of gas in the tube, the cathode temperature, the level of nuclear radiation, and the lead-wire resistance. As the cathode temperatures increased, the first stable value reached after breakdown was lower in voltage and higher in current, which is illustrated by comparison of curves II and IV of figure 11. These curves are for the same tube. The fact that the discharge can be stably sustained in these irradiated xenon diodes at voltages as low as 1.0 to 2.0 volts is quite interesting. Of course, this voltage is sensitive to the relative difference in work function between the cathode and anode. Unlike the situation in cesium thermionic converters, the work function of the cathode in these tubes is prob- 
ably lower than that of the anode. If the work function of the anode could be lowered, the characteristics could probably be shifted to the left (refs. 4 and 5) and would result in a lower value than 1.0 volt for the voltage needed to stably sustain the discharge.

Early breakdown effects at voltages lower than the first excitation potential in irradiated inert-gas diodes is attributed to the existence of a high density of excited states in the nuclear irradiated gas plasma (ref. 6). These excited states can be ionized by lowenergy electrons and result in the initiation of the breakdown phenomena. Although the details of the breakdown characteristics in figure 11 are not uncommon, the stability of the xenon-gas discharge at such small applied voltages is unusual.

Further studies of the variation of discharge characteristics with increased nuclear radiation intensity and cathode temperature may lead to some interesting applications such as an inert-gas-type thermionic converter. Further studies would include use of a higher temperature cathode (e.g., thoriated tungsten) in a xenon-filled diode at higher radiation levels (e. g., gamma dose rate to $1.5 \times 10^{9} \mathrm{rads} / \mathrm{hr}\left(1.5 \times 10^{7} \mathrm{~J} /(\mathrm{kg})(\mathrm{hr})\right.$ ). If these studies were made, results such as those illustrated in figure 12 might be predicted. Curve I illustrates the type of data described in this report with a lowtemperature thermionic emitter. Some features of this curve are similar to those obtained from cesiated devices (ref. 7). Region A to C corresponds to the unignited mode and $\mathrm{D}$ to $\mathrm{E}$ to the ignited mode. Region $\mathrm{B}$ is the "apparent saturation" region, and $\mathrm{C}$ is the preignited range. Breakdown occurs at $\mathrm{D}$, and $\mathrm{E}$ is the range of the ignited mode. At higher radiation levels and higher emitter temperature, curve II may be obtainable. Curve II still assumes that the cathode work function is lower than that of the anode. The simpler characteristic of curve II should result from increased volume ionization (ref. 7). The increased radiation increases the density of excited states in the rare gas plasma, and the higher emitter temperature increases the likelihood of ignition of the plasma at low voltages. If curve II could be obtained, the efficiency of the device as a thermionic converter could be greatly improved by lowering the anode work function. The results of such a conversion are illustrated by the range (III). In this range, the collector work function has been lowered over a range of values. This reduction could be accomplished by adding enough cesium to the device, which originally generated curve II, so as to form a complete or partial monomolecular layer of cesium on the collector. If these improvements can be achieved at reasonable emitter temperatures and nuclear radiation levels, an inert-gas nuclear thermionic device would be feasible and practical.

\section{CONCLUSIONS}

Unusual breakdown phenomena in nuclear irradiated xenon-filled thermionic diodes 
have been measured as a function of xenon pressure, nuclear radiation intensity, emitter temperature, and electrode spacing. The similarity between some of these discharge curves and data obtained for low-temperature cesium converters suggests that further studies at higher emitter temperatures and nuclear radiation fluxes are desirable. Such studies may lead to (1) a better understanding of the basic principles of thermionic conversion and (2) the possibility of designing a practical inert-gas-filled nuclear-irradiated thermionic converter.

Lewis Research Center,

National Aeronautics and Space Administration, Cleveland, Ohio, November 16, 1967, 120-27-05-09-22.

\section{REFERENCES}

1. Forman, R.: Electrical Properties of Inert Gas Plasmas Generated in Thermionic Cold-Cathode Diodes by Radiation in a Nuclear Reactor. J. Appl. Phys., vol. 36, no. 4, Apr. 1965, pp. 1344-1350.

2. Levi, Roberto: Improved "Impregnated Cathode." J. Appl. Phys., vol. 26, no. 5, May 1955, p. 639.

3. Forman, R.: Electrical Conduction and Breakdown in High-Pressure (0. 25 to $300 \mathrm{~mm}$ ) Rare Gases. J. Appl. Phys., vol. 32, no. 9, Sept. 1961, pp. 1651-1658.

4. Webster, H. F.: Thermionic Emission from a Tantalum Crystal in Cesium or Rubidium Vapor. J. Appl. Phys., vol. 32, no. 9, Sept. 1961, pp. 1802-1803.

5. Forman, R.; and Ghormley, J. A. : Effect of Daughter Rb ${ }^{85}$ on the Characteristics of a Thermionic Diode Containing $\mathrm{Kr}^{85}$. J. Appl. Phys., vol. 34, no. 8, Aug. 1963, pp. 2498-2499.

6. Forman, R.: Onset of Breakdown at Voltages Below Ionization Potential in HighPressure Thermionic Diodes. J. Appl. Phys., vol. 35, no. 2, Feb. 1964, pp. 261-264.

7. Bullis, Robert H. ; Hansen, Lorin K. ; Warner, Charles; Houston, John M. ; Koskinen, Michael F.; and Rasor, Ned S.: The Plasma Physics of Thermionic Converters. J. Appl. Phys., vol. 38, no. 9, Aug. 1967, pp. 3425-3438. 


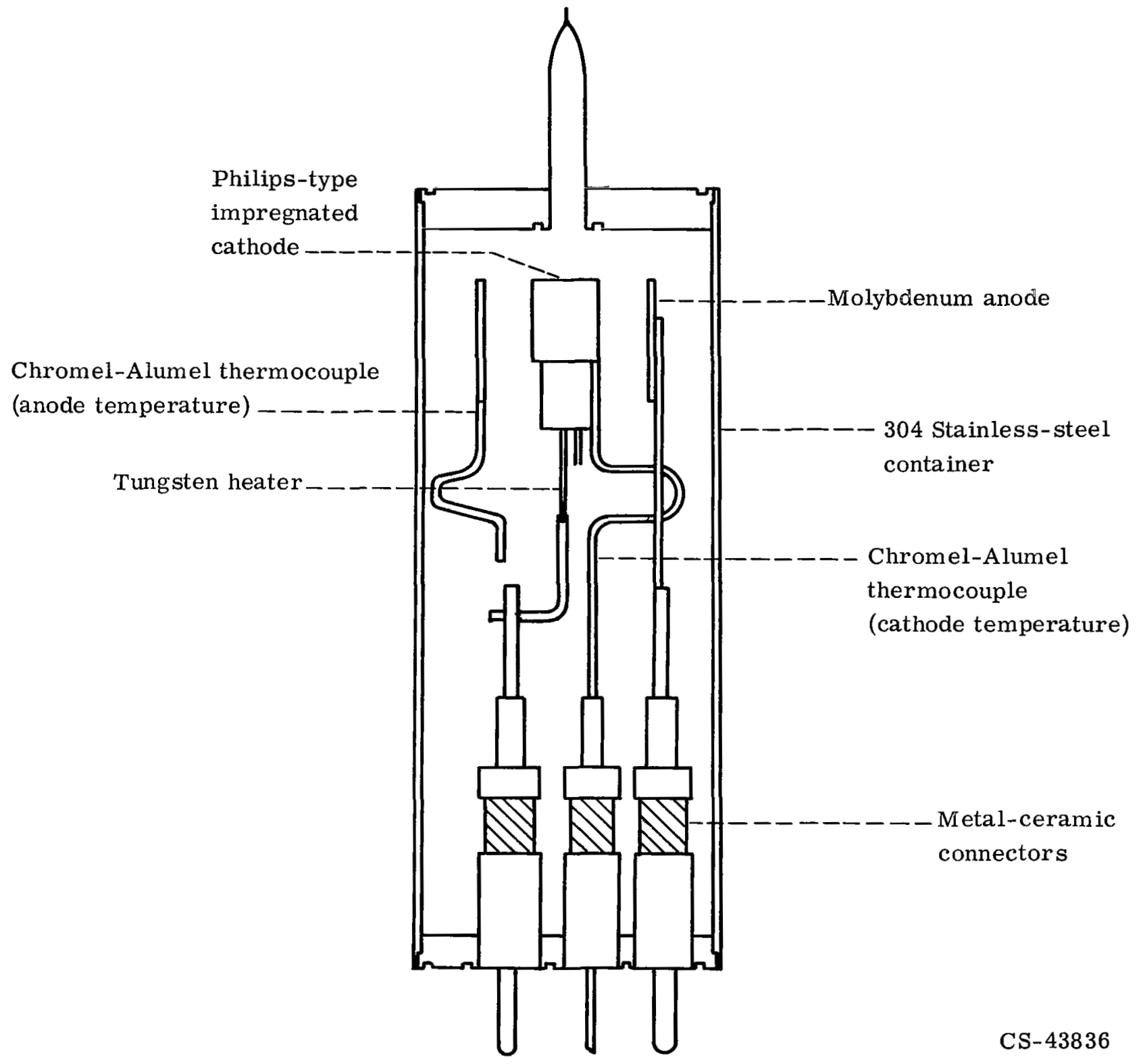

Figure 1. - Schematic drawing of thermionic diode with 0.75 -centimeter cathode-anode spacing. 


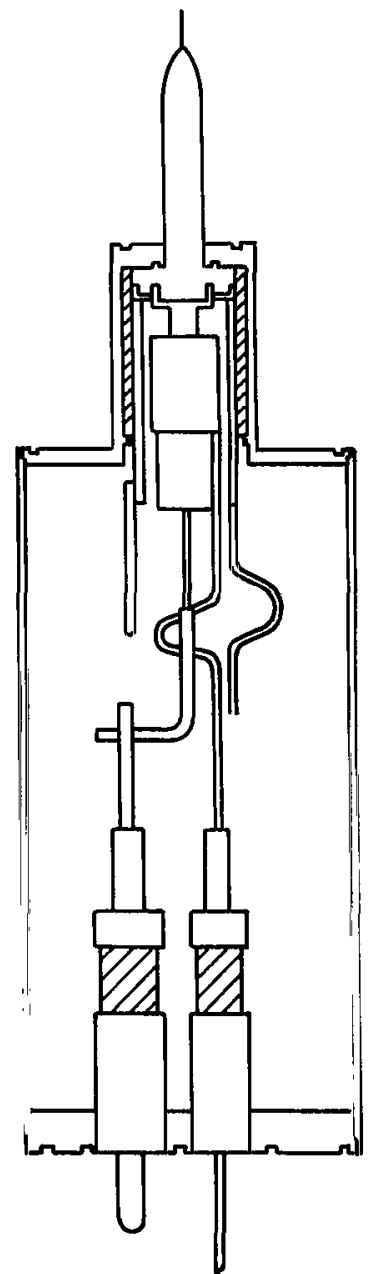

(a) Complete tube.

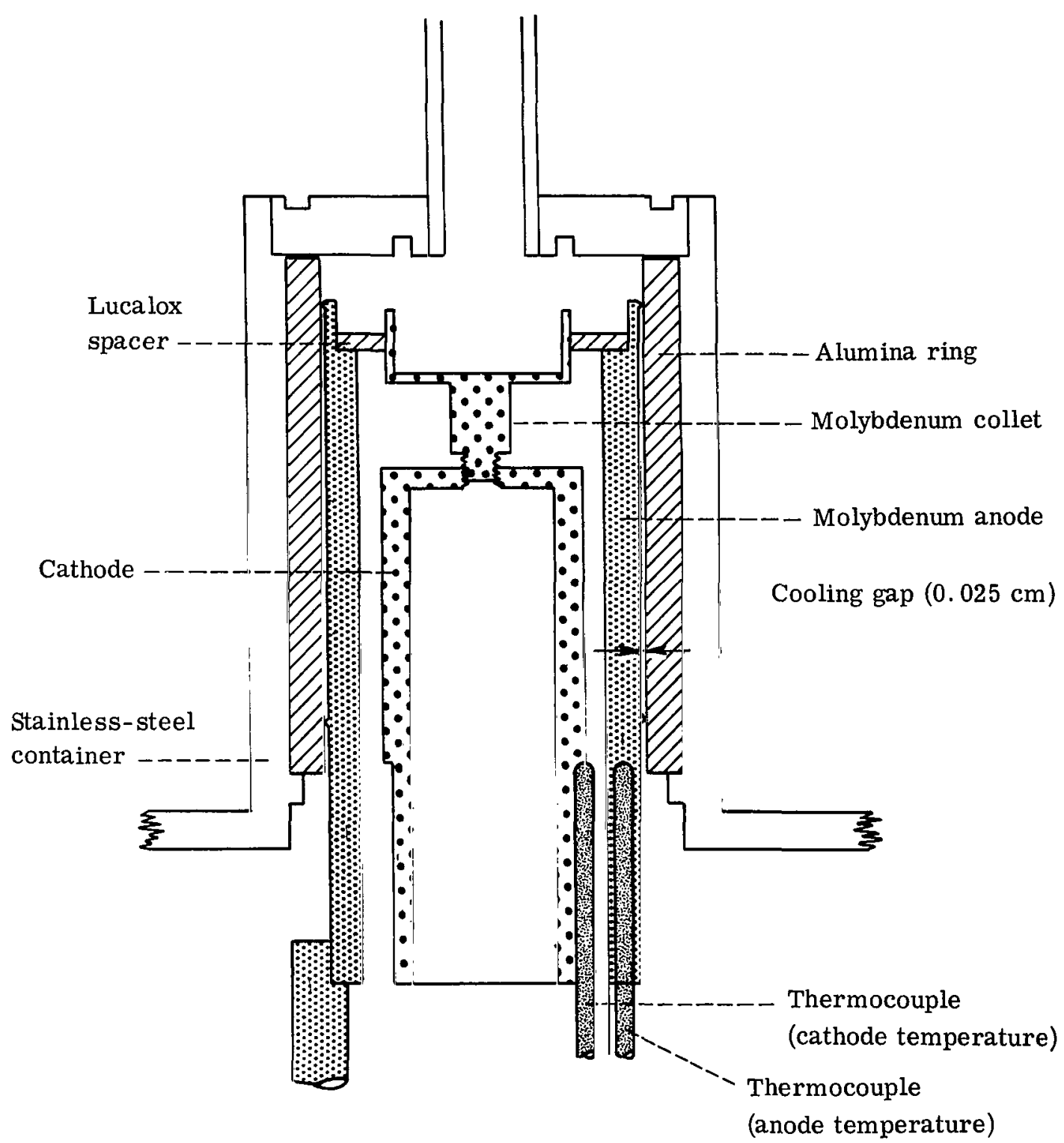

(b) Details of cathode-anode structure.
CS- 43838

Figure 2. - Schematic drawings of thermionic diode with interelectrode spacing of 0.1 centimeter or less. 


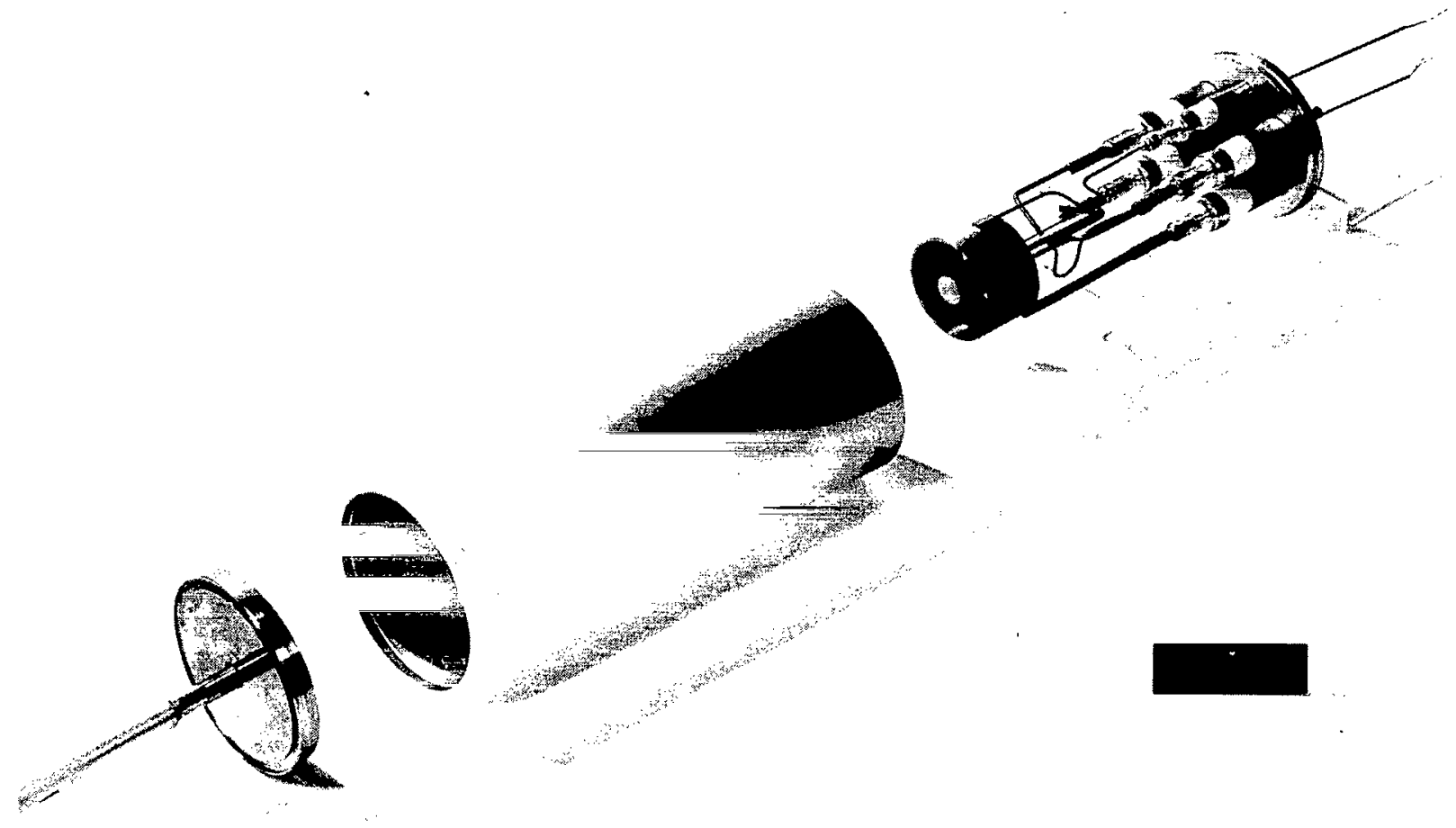

C-67. -748

Figure 3. - Unassembled tube with 0.75 -centimeter cathode-anode spacing.

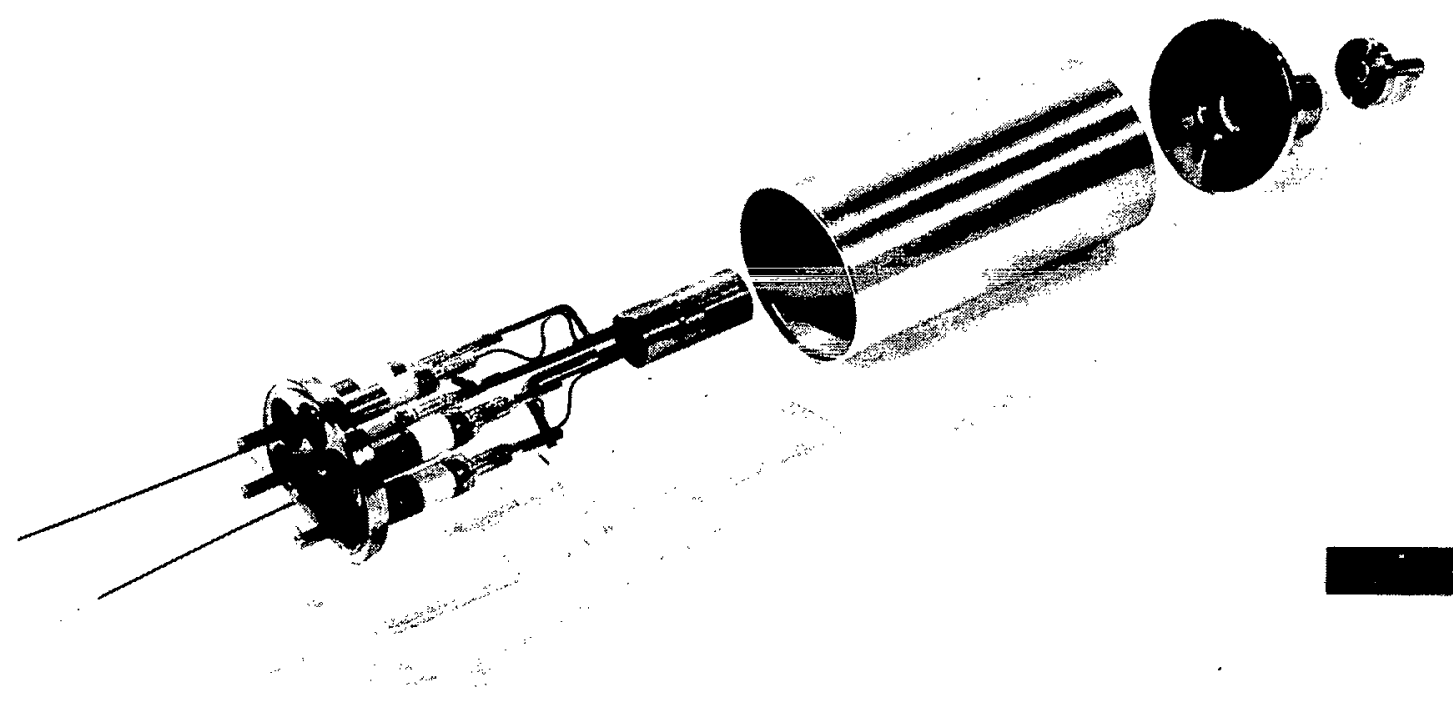

C-67-996

Figure 4. - Unassembled tube with interelectrode spacing of 0.1 centimeter (or less). 


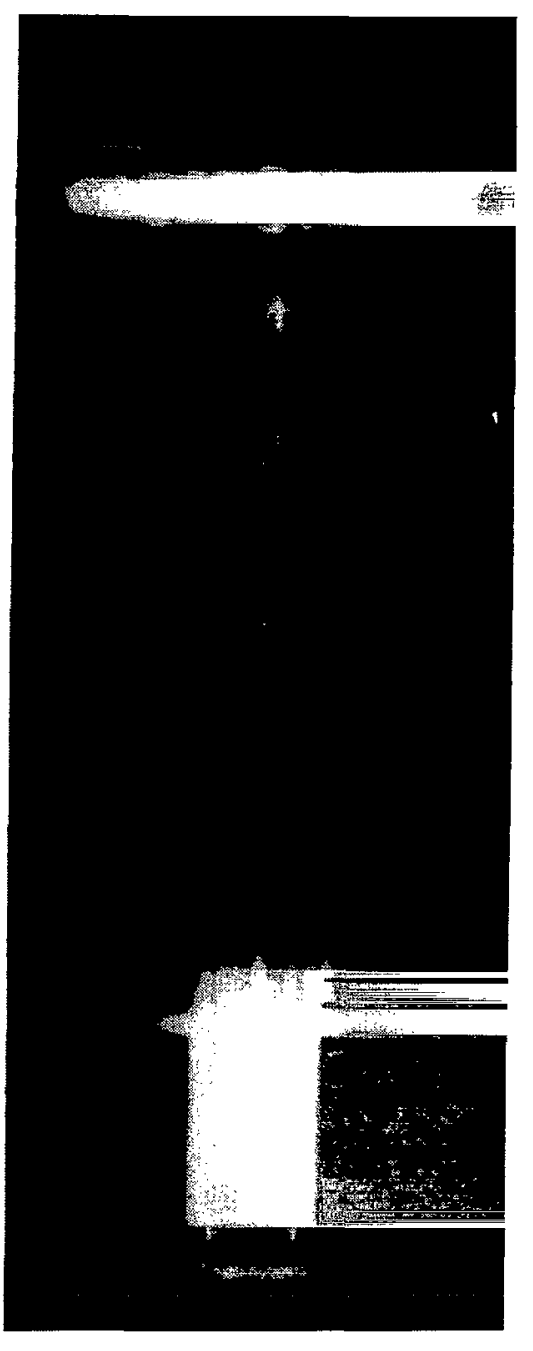

Figure 5. - Radiograph of tube with 0.05-centimeter cathode-anode spacing.

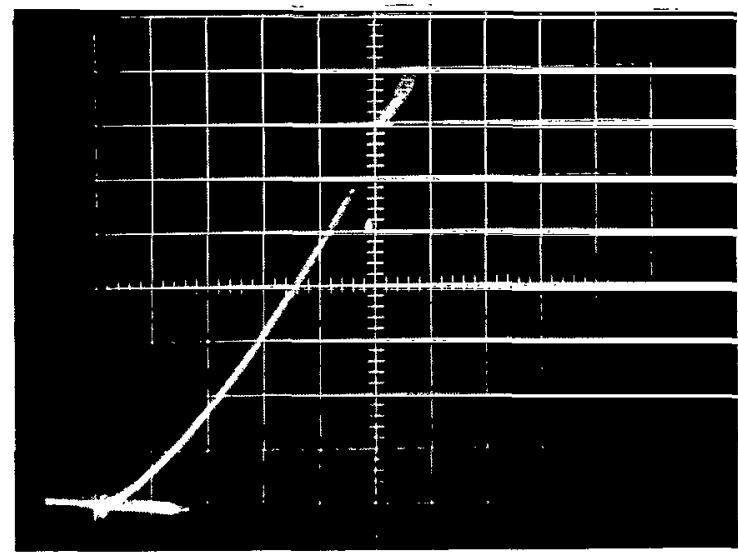

(a) Vacuum characteristic. Horizontal sensitivity, 30 volts per division; vertical sensitivity, 1 ampere per division; cathode temperature, $1108^{\circ} \mathrm{C}$; anode temperature, $800^{\circ} \mathrm{C}$.

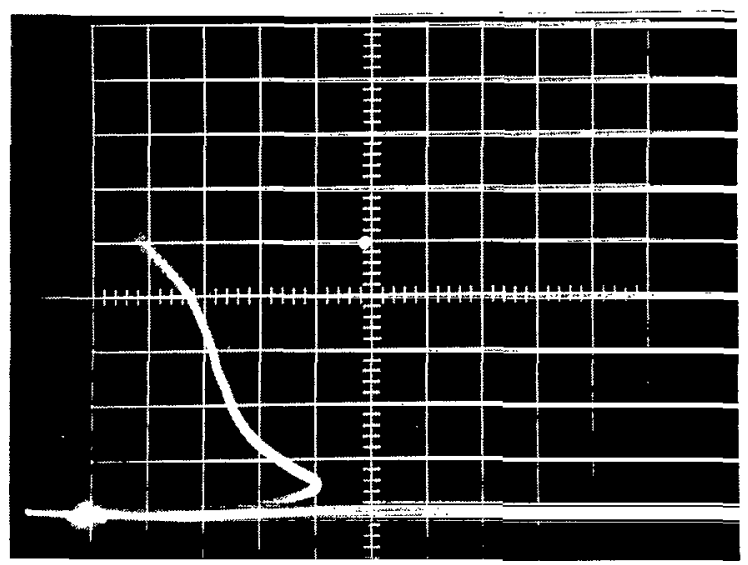

(b) Characteristics after diode is filled with 78 -torr $\left(1.0 \times 10^{4}\right.$ $\mathrm{N} / \mathrm{m}^{2}$ ) xenon. Horizontal sensitivity, 3 volts per division; vertical sensitivity, 1 ampere per division; cathode temperature, $1115^{\circ} \mathrm{C}$; anode temperature, $655^{\circ} \mathrm{C}$.

Figure 6. - Oscillograms of current-voltage characteristics of tube with electrode spacing of 0.05 centimeter. 

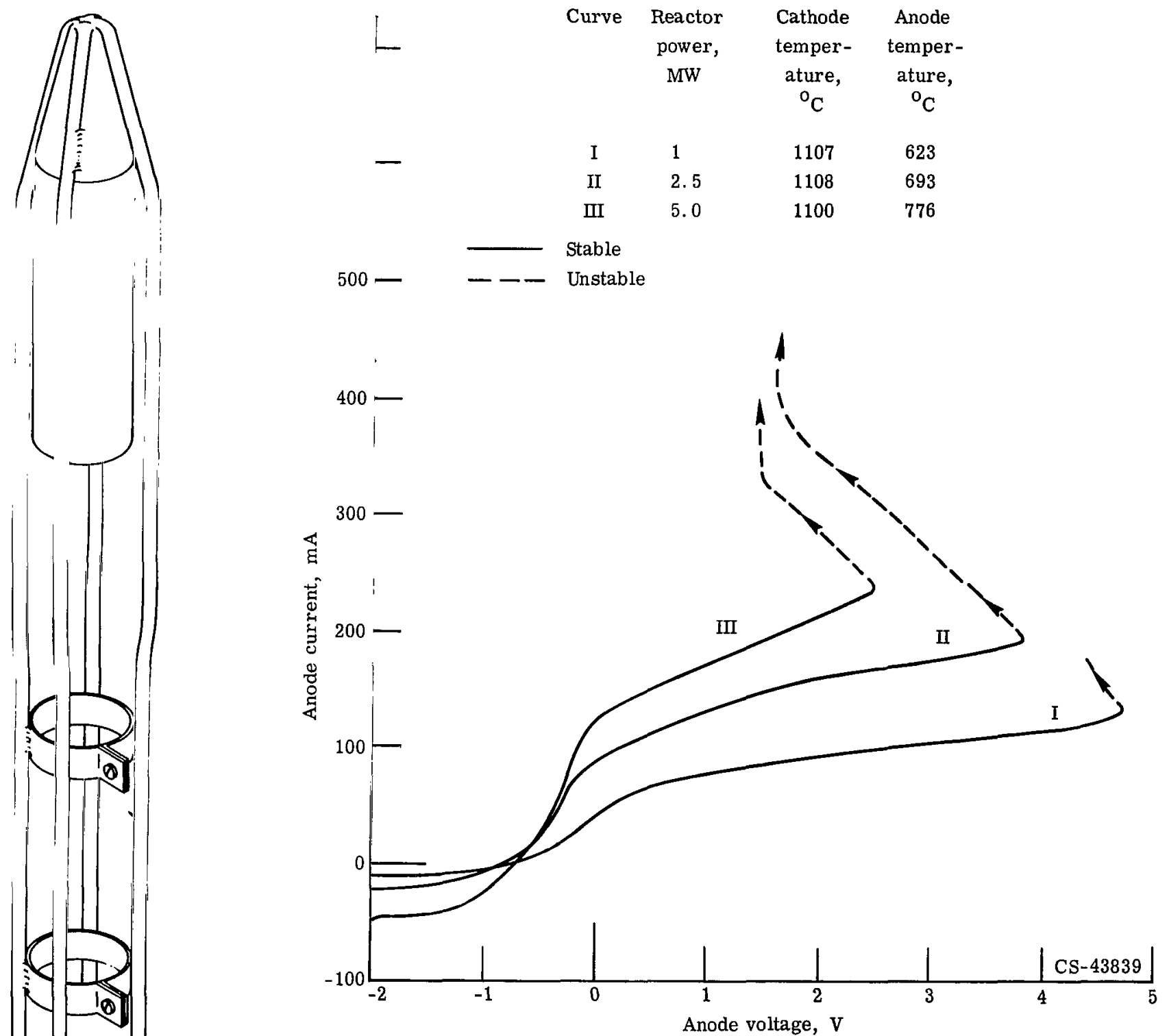
rocket-type tube holder.

Figure 8. - Effect of reactor power on current-voltage characteristics of irradiated thermionic diode containing 10 torr $\left(1.3 \times 10^{3} \mathrm{~N} / \mathrm{m}^{2}\right)$ of xenon and having an electrode spacing of 0.75 centimeter. 


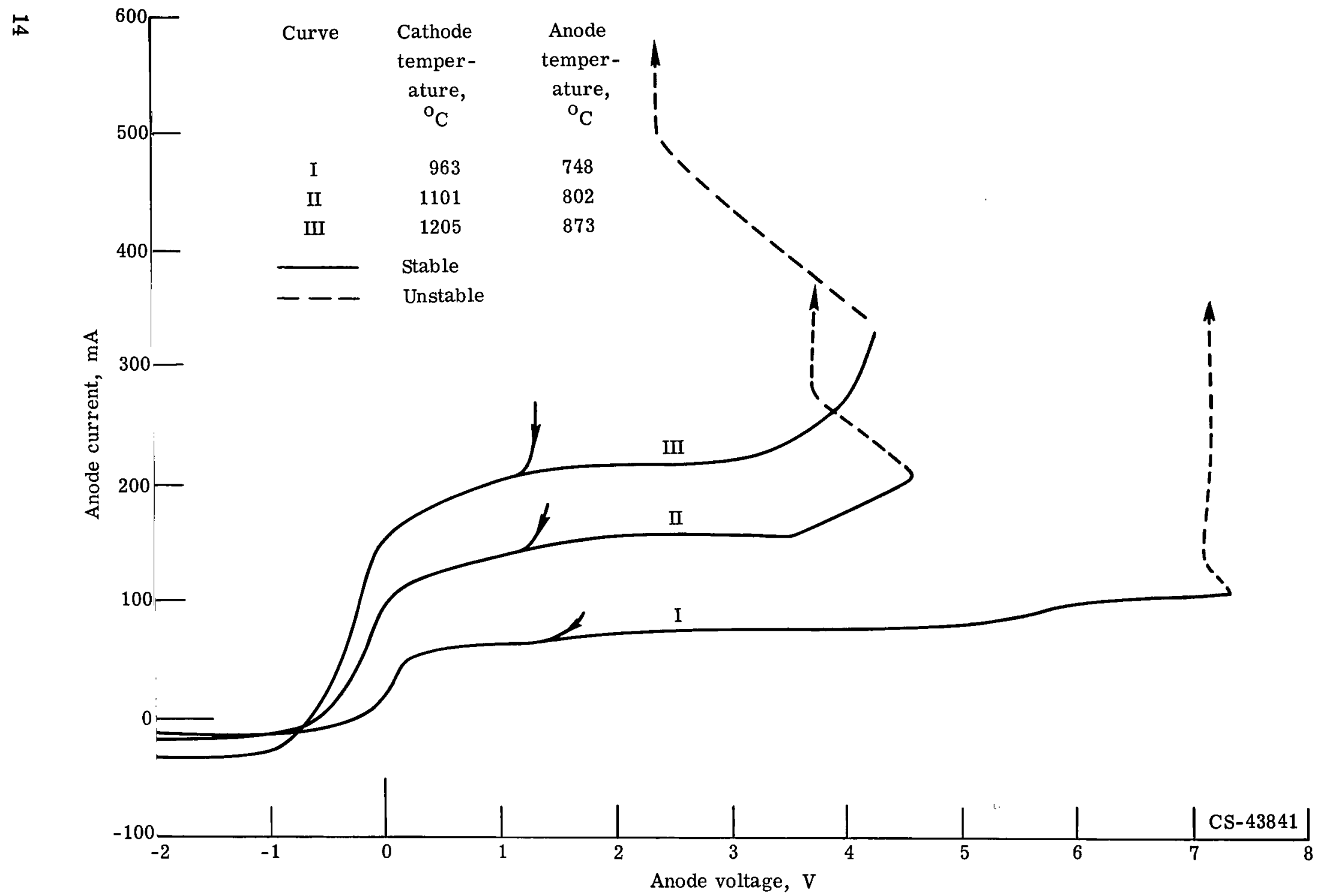

Figure 9. - Effect of cathode temperature on current-voltage characteristics of irradiated thermionic diode containing 157 torr $\left(2.04 \times 10^{4} \mathrm{~N} / \mathrm{m}^{2}\right)$ of xenon and having an interelectrode spacing of 0.05 centimeter. Measurements were made at reactor power of 5.0 megawatts. 


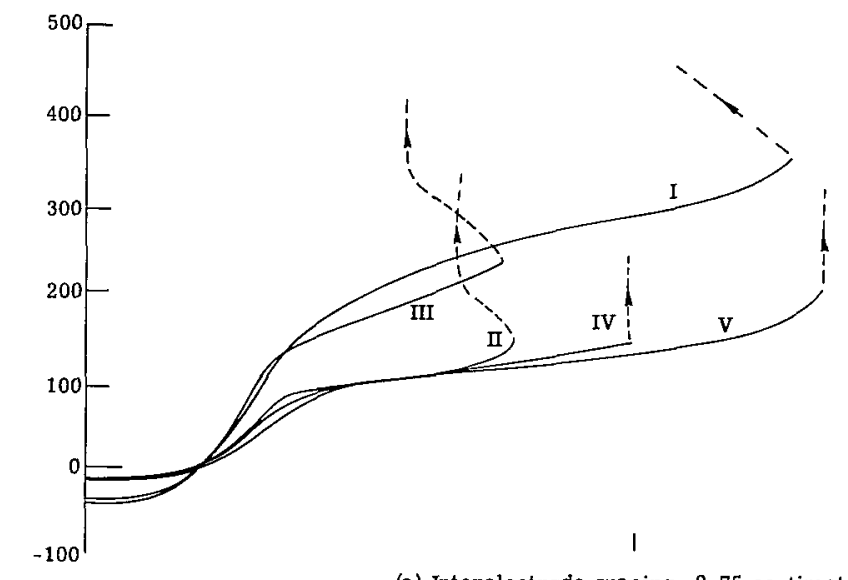

(a) Interelectrode spacing, 0.75 centimeter.

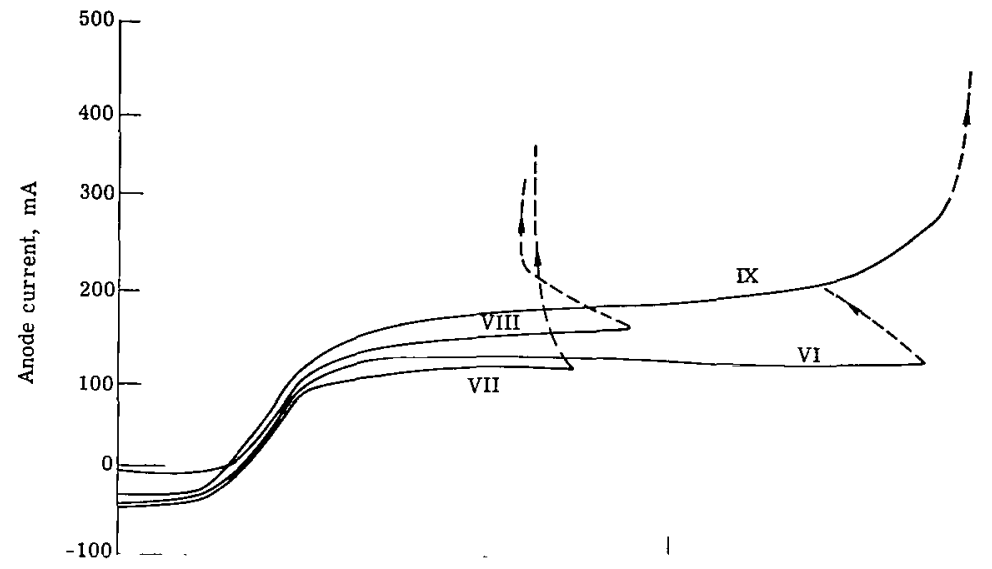

(b) Interelectrode spacing, 0.1 centimeter.

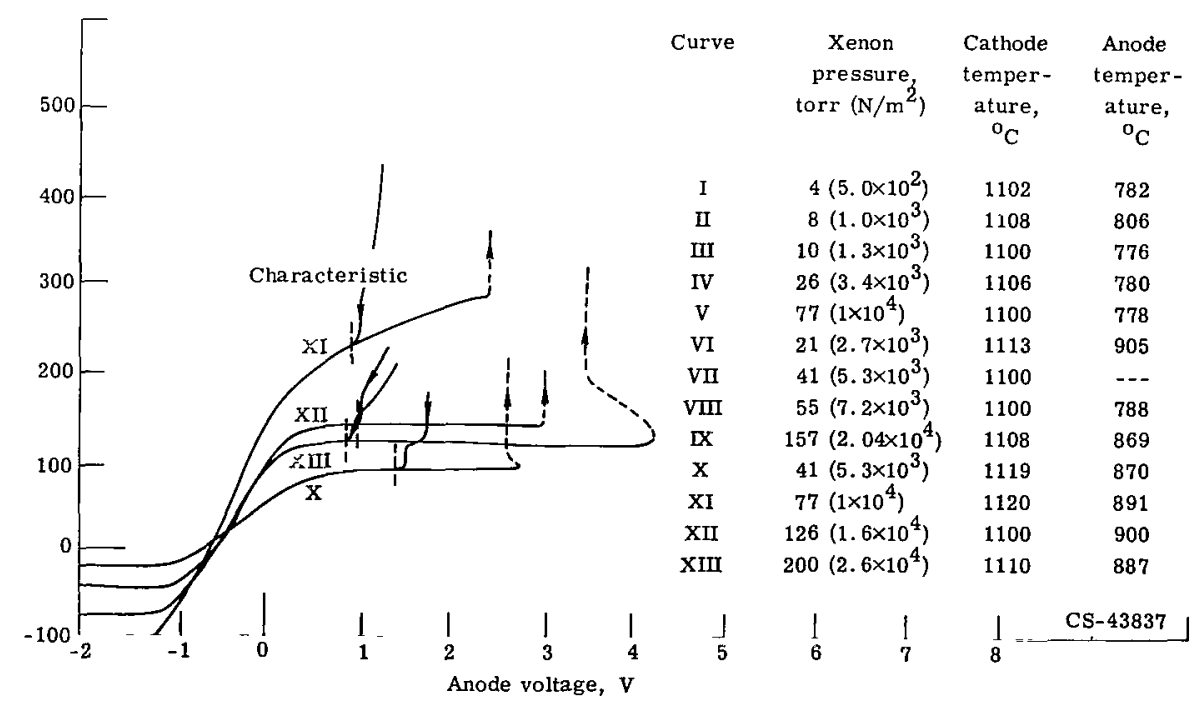

(c) Interelectrode spacing, 0.025 centimeter.

Figure 10. - Effect of xenon pressure on current-voltage characteristics of irradiated thermionic diodes. Reactor power, 5.0 megawatts. 


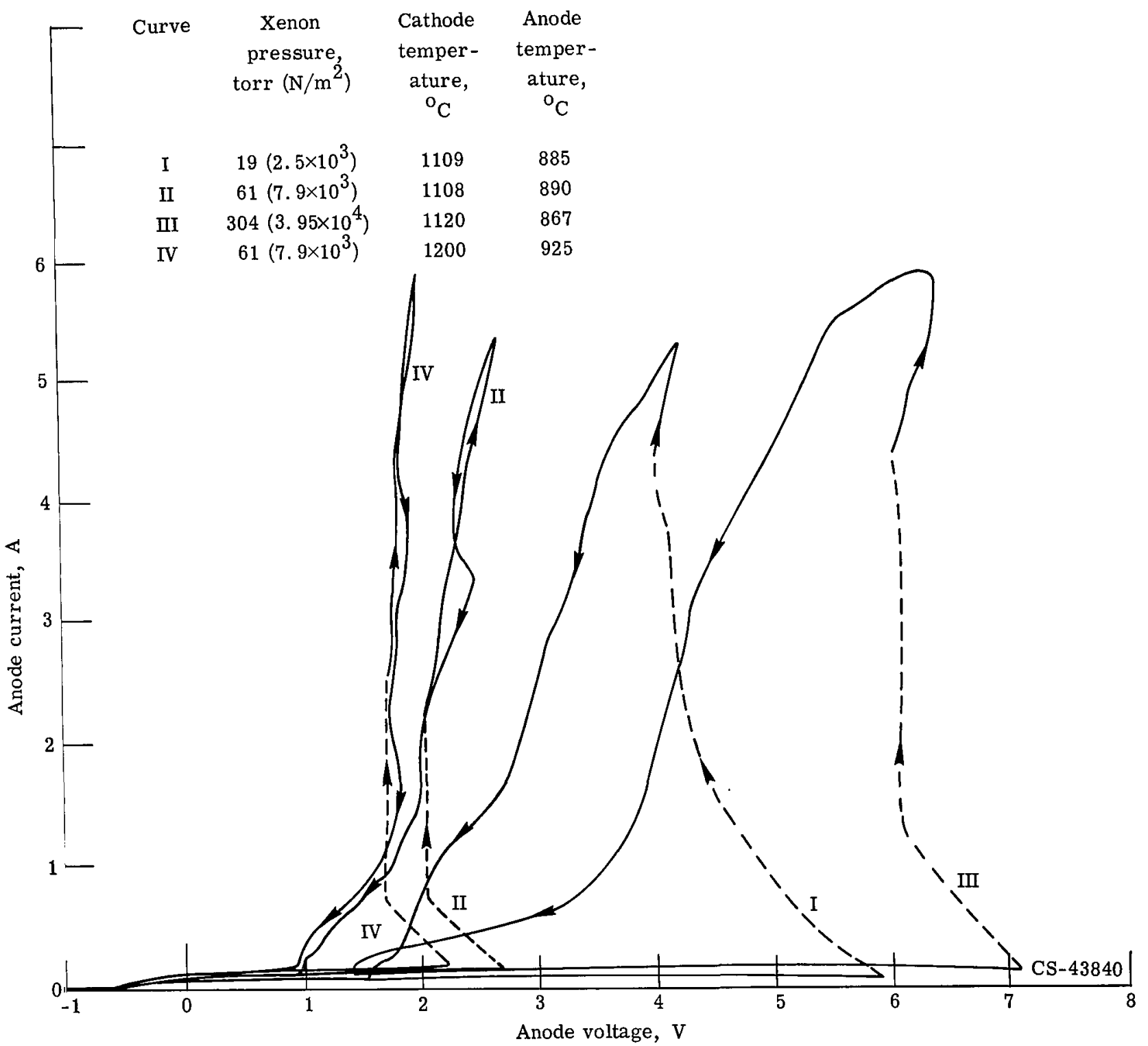

Figure 11. - Effect of xenon-gas pressure on breakdown phenomena in irradiated thermionic diodes with an interelectrode spacing of 0.050 centimeter and different pressures of xenon as the filling gas. Reactor power, 5.0 megawatts. 


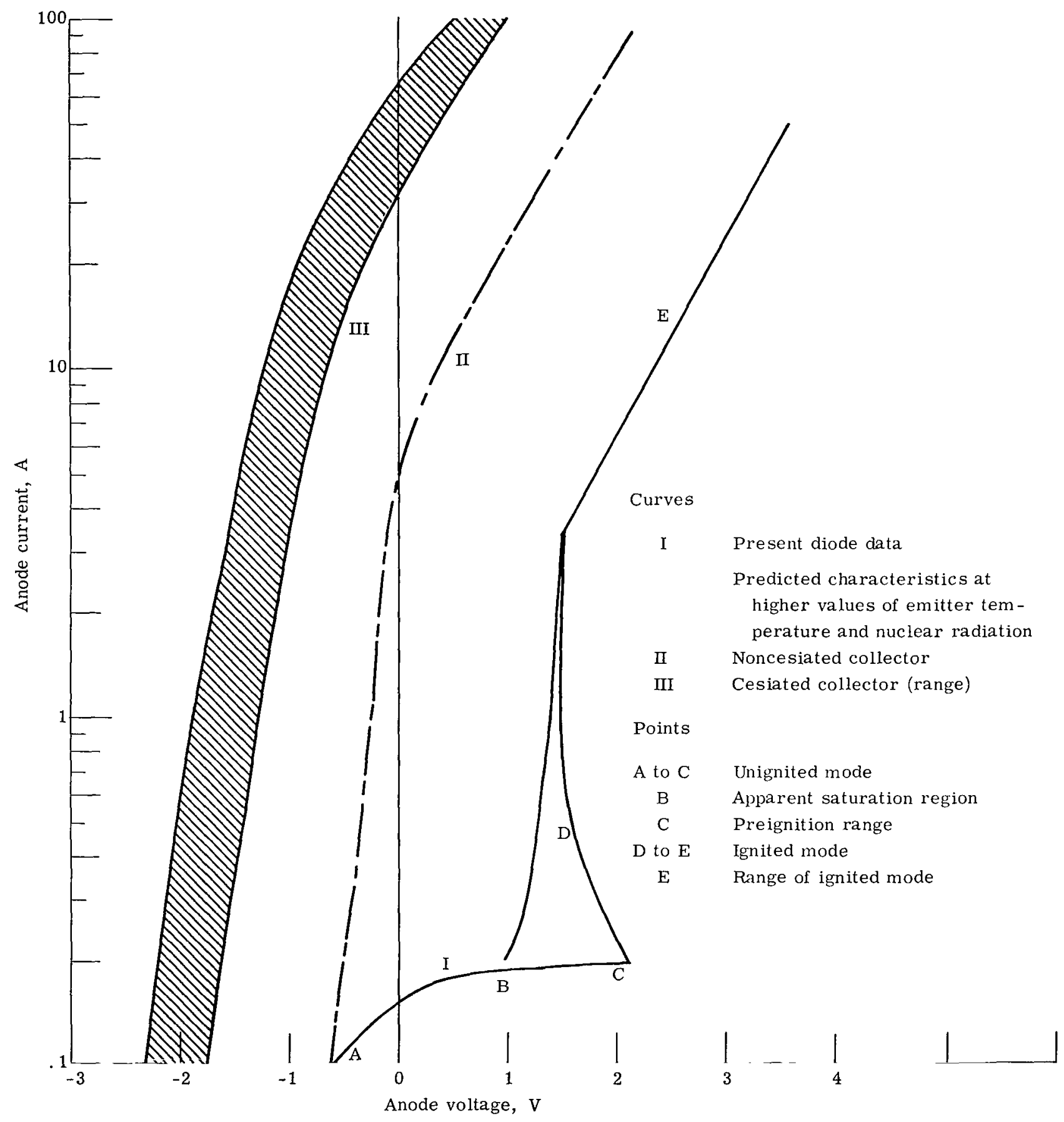

Figure 12. - Current-voltage characteristics of inert-gas-filled nuclear-irradiated diodes. 
"The aeronatical and space activities of the United States sball be conducted so as to contribute . . . to the expansion of buman knowledge of phenomena in the atmospbere and space. The Administration shall provide for the widest practicable and appropriate dissemination of information concerning its activities and the results thereof."

-National Aeronautics and Space Act of 1958

\section{NASA SCIENTIFIC AND TECHNICAL PUBLICATIONS}

TECHNICAL REPORTS: Scientific and technical information considered important, complete, and a lasting contribution to existing knowledge.

TECHNICAL NOTES: Information less broad in scope but nevertheless of importance as a contribution to existing knowledge.

TECHNICAL MEMORANDUMS: Information receiving limited distribution because of preliminary data, security classification, or other reasons.

CONTRACTOR REPORTS: Scientific and technical information generated under a NASA contract or grant and considered an important contribution to existing knowledge.

TECHNICAL TRANSLATIONS: Information published in a foreign language considered to merit NASA distribution in English.

SPECIAL PUBLICATIONS: Information derived from or of value to NASA activities. Publications include conference proceedings, monographs, data compilations, handbooks, sourcebooks, and special bibliographies.

TECHNOLOGY UTILIZATION PUBLICATIONS: Information on technology used by NASA that may be of particular interest in commercial and other non-aerospace applications. Publications include Tech Briefs, Technology Utilization Reports and Notes, and Technology Surveys.

Details on the availability of these publications may be obtained from:

SCIENTIFIC AND TECHNICAL INFORMATION DIVISION

NATIONAL AERONAUTICS AND SPACE ADMINISTRATION

Washington, D.C. 20546 